\title{
Evaluasi User Experience Menggunakan Pendekatan Heuristic Pada Sistem Informasi Akademik Universitas Bina Darma Palembang
}

\author{
Ledy Armyoktora', Ari Muzakir² \\ 1,2Sistem Informasi, Bina Darma Palembang, Indonesia \\ Email : Ledyarmyoktora@gmail.com¹, arimuzakir@binadarma.ac.id ${ }^{2}$
}

\begin{abstract}
The Academic of Information System has been implemented at Bina Darma Unversity Palembang for a long time. The Academic of Information System is a web-based system facility that contains profiles and developments of student academic activities. The purpose of this study to evaluate sisfo to measure user perceptions and determine user satisfaction with Sisfo using a Heauristic Evauation approach. From 39 questionnaire statements filled out by 98 respondents, it was found that Sisfo was in good condition and did not require repairs.
\end{abstract}

Keywords: Academic of Information System, Bina Darma Unversity, Heauristic Evauation

\section{PENDAHULUAN}

SISFO atau Sistem Informasi Akademik adalah sebuah sistem aplikasi yang dibuat secara khusus untuk mengelola data administrasi akademik dalam dengan penerapan teknologi komputerisasi sehingga pengelolaan administrasi akademik dapat dikelola dengan baik dan dapat menyajikan informasi secara tepat dan cepat [1], biasanya berisikan profil dan perkembangan aktifitas akademik mahasiswa dari pemiliha $\mathrm{n}$ mata kuliah hingga laporan penilaian, adapun didalamnya juga berisikan beberapa informasi yang ditujukan kepada mahasiswa, seperti kegiatan universitas atau himbauan untuk mahasiswa. SISFO ini berada di jaringan Universitas Bina Darma Palembang dengan alamat http://sisfo.binadarma.ac.id.

SISFO sebagai sistem informasi akademik yang selalu digunakan oleh mahasiswa harus menjadi sistem web yang mudah digunakan dan bernilai informatif demi kelancaran perkuliahan dan aktifitas mahasiswa sebagai pengguna dalam keseharian. Pengalaman pengguna dalam hal ini mahasiswa 


\section{Journal of Software Engineering Ampera}

Vol. 2, No. 3, October 2021 e-ISSN: 2775-2488

https://journal-computing.org/index.php/journal-sea/index

dapat menjadi tolak ukur penerimaan terhadap SISFO maka dilakukan evaluasi agar mengetahui bagaimana persepsi pengguna terhadap SISFO.

User Experience (UX) merupakan bagaimana layanan atau produk bekerja ketika seseorang datang atau menggunakannya, bukan mengenai kinerja internalnya untuk itu UX merupakan bagian yang penting dalam berbisnis [2]. Dalam penelitian Rifda, teori Rubinoff mengatakan bahhwa salah satu elemen dari UX adalah usability [3]. Pendekatan melalui aspek usability dapat digunakan dalam menganalisis user experience pada UBD menggunakan metode Heuristic evaluation. usability adalah sebuah ukuran kualitas dari pengalaman pengguna ketika berinteraksi dengan sebuah produk atau sistem, yang dapat berupa sebuah halaman web, perangkat lunak, teknologi mobile ataupun perangkat apapun [4]. Adapun hal-hal yang perlu dievaluasi dari SISFO tampilan yang kurang efektif dan efisien, tampilan SISFO juga tidak mengikuti perkembangan desain terkini (modern) dan tampilan SISFO sangat kurang responsive terhadap perubahan menu ketika error yang berganti. Hal lainnya yang juga perlu ditingkatkan ialah informasi kegiatan perkuliahan yang jelas, serta perkembangan informasi aktifitas belajar mengajar yang kurang berfungsi sehingga perlu ada evaluasi secara detail untuk mengukur kemudahan penggunaan SISFO bagi user atau mahasiswa dari segi kemudahan dipelajari, digunakan, kepuasan dan tingkat efisiensi, hal ini berguna untuk kelangsungan dan pengembangan Uiversitas Bina Darma ke depan sebagai kampus dengan basis teknologi yang maju. Berdasarkan penjelasan diatas, pada penelitian ini menggunakan Metode Heuristic Evaluation untuk mengukur pengalaman pengguna terhadap SISFO UBD. Evaluasi heuristik adalah suatu cara pemeriksaan usability untuk perangkat lunak komputer yang membantu mengenali masalah-masalah usability pada rancangan antarmuka [5]. Penulis akan membahas hasil evaluasi dari sebaran kuesioner berjumlah 37 pernyataan kepada 97 responden pengguna SISFO UBD.

Beberapa penelitian terkait yang untuk mendukung penelitian ini antara lain : Prematara Oktabareki pada jurnalnya yang berjudul Analisis UI/UX pada Sistem Informasi Akademik Universitas Sriwijaya Dengan Menggunakan Metode Heuristic Evaluation, hasil dari penelitiannya menerangkan bahwa Sistem Informasi Akademik Universitas Sriwijaya sudah cukup baik [6]. Aditya Kurniawan dalam jurnalnya yang berjudul Evaluasi User Experience pada Website UNDISKHA dengan Metode Heuristic Evaluation dan Persona menggunakan Severity Rating untuk mengkategorikan tingkat keparahan 


\section{Journal of Software Engineering Ampera}

Vol. 2, No. 3, October 2021 e-ISSN: 2775-2488

https://journal-computing.org/index.php/journal-sea/index

masalah [7]. Ni Ketut Thrisnandha Purnama pada jurnalnya yang berjudul Usability Testing Menggunakan Heuristic Evaluastion pada Aplikasi EMusrenbang [8]. Sebelum evaluasi dilakukan maka harus dilakukan uji reabilitas instrumen menggunakan rumus Alpha Cronbach, seperti yang dilakukan oleh $\mathrm{Ni}$ Ketut Thrisnandha Purnama. Kisi instrumen kuesioner merujuk pada penelitian Ghina dalam jurnalnya yang berjudul Analisis User Experiance Terhadap Website Perpustakaan Universitas Gunadarma Dengan Metode Heuristic Evaluation, hasil dari penelitian tersebut website perpustakaan Universitas Gunadarma dalam keadaan baik [9]..

\section{METODE PENELITIAN}

\subsection{Evaluasi Heuristik}

Evaluasi heuristik adalah suatu cara pemeriksaan usability untuk perangkat lunak komputer yang membantu mengenali masalah-masalah usability pada rancangan antarmuka. Evaluasi heuristik memeriksa antarmuka dan memutuskan apakah rancangan tersebut sesuai dengan heuristik yang ada. Evaluasi heuristik banyak dipakai pada rancangan dengan jangka waktu perancangan yang singkat dan dengan dana yang terbatas [5].

Evaluasi heuristik dipilih karena evaluasi heuristik dapat dilakukan dengan cepat, mudah dan dengan biaya yang rendah, dibandingkan dengan evaluasi usability lainnya. Evaluasi heuristik hanya menggunakan kumpulan penguji heuristik dengan jumlah yang kecil, yang melakukan evaluasi heuristik dengan waktu yang singkat, sehingga biaya yang dikeluarkan bisa diminimalkan.

Tujuan utama evaluasi heuristik adalah untuk mengidentifikasi masalah yang berkaitan dengan rancangan antarmuka. Metode ini dikembangkan oleh Jakob Nielsen berdasarkan pengalaman mengajar dan konsultasi selama beberapa tahun pada bidang usability. Evaluasi heuristik adalah salah satu jenis evaluasi usability yang paling banyak digunakan. Kepopuleran evaluasi heuristik adalah karena evaluasi ini cepat, mudah dan murah dalam implementasi. Pada dasarnya, evaluasi heuristik tidak mudah dilakukan karena sangat sulit bagi seorang individu untuk dapat menemukan semua masalah usability pada suatu rancangan antarmuka. Sepuluh aspek yang dinilai dalam metode Heuristic Evaluation menurut Jacob Nielsen dan yang penulis masukkan dalam kuisionernya adalah sebagai berikut: 


\section{Journal of Software Engineering Ampera}

Vol. 2, No. 3, October 2021 e-ISSN: 2775-2488

https://journal-computing.org/index.php/journal-sea/index

Tabel 1. Heuristic Evaluation

\begin{tabular}{|c|c|c|}
\hline NO & Variabel & Kode \\
\hline 1 & Visibilitas dari status sistem (Visibilityof|SystemStatus) & $\mathrm{X} 1$ \\
\hline 2 & $\begin{array}{l}\text { Kesesuaian antara sistem dan dunia nyata (Match } \\
\text { BetweenSystemandtheRealWorld) }\end{array}$ & $\mathrm{x} 2$ \\
\hline 3 & $\begin{array}{l}\text { Kendali dan kebebasan pengguna (User } \\
\text { ControlandFreedom) }\end{array}$ & X3 \\
\hline 4 & Standar dan Konsistensi (ConsistencyandStandards) & X4 \\
\hline 5 & Pencegah Kesalahan (ErrorPrevention) & X5 \\
\hline 6 & $\begin{array}{l}\text { Bantuan pengguna untuk mengenali, mendiagnosa, dan } \\
\text { mengatasi masalah (Recognitionrather thanRecall) }\end{array}$ & $x 6$ \\
\hline 7 & Fleksibilitas dan efesiensi (FlexibilityandEfficiencyofUse) & $\mathrm{X} 7$ \\
\hline 8 & $\begin{array}{l}\text { Estetika dan desain yang minimalis } \\
\text { (AestheticandMinimalistDesign) }\end{array}$ & $\mathrm{x} 8$ \\
\hline 9 & $\begin{array}{l}\text { Pertolongan pengguna mengenal, berdialog dan } \\
\text { memperbaiki kesalahan (HelpUsers } \\
\text { Recognize, Diagnoseand Recover from Errors) }\end{array}$ & X9 \\
\hline 10 & $\begin{array}{l}\text { Fitur Bantuan dan Dokumentasi } \\
\text { (HelpandDocumentation ) }\end{array}$ & $\mathrm{X} 10$ \\
\hline
\end{tabular}

\subsection{Severity Rating}

Severity Rating dapat digunakan untuk mengalokasikan sebagian besar sumber daya untuk memperbaiki masalah yang paling serius dan juga dapat memberikan perkiraan kasar tentang perlunya upaya penanggulangan [5]. Perhitungan pada Heuristic Evaluation menggunakan persamaan Severity Rating yaitu:

1. Persamaan satu

$$
\sum H x=(0 * x)+(1 * x)+(2 * x)+(3 * x)
$$

Dengan $\sum H x=$ jumlah skor rating dari sub aspek usability dalam setiap aspek usability $(\mathrm{H} 1 \ldots . . \mathrm{H} 2 \ldots \ldots . . . \mathrm{H} 10)$

$x=$ poin usability, bernilai $1 / 0$

Berikutnya untuk menghasilkan nilai Severity Rating dari masing-masing aspek Usability

2. Persamaan dua 


\section{Journal of Software Engineering Ampera}

Vol. 2, No. 3, October 2021 e-ISSN: 2775-2488

https://journal-computing.org/index.php/journal-sea/index

$$
s v=\sum_{n}^{H x}-
$$

sv = hasil severity rating dalam satu aspek usability

$\mathrm{n}$ = banyaknya sub aspek usability dalam setiap aspek usability

Tabel 2. Skala Nilai Severity Rating

\begin{tabular}{|c|c|}
\hline Severity Rating & Keterangan \\
\hline 0 & $\begin{array}{l}\text { Tidak ditemukan adanya permasalahan atau kekurangan } \\
\text { pada sistem. }\end{array}$ \\
\hline 1 & $\begin{array}{l}\text { Kategori cosmetic problem, masalah tidak terlalu } \\
\text { mempengaruhi pengguna. Perbaikan tidak terlalu } \\
\text { dibutuhkan }\end{array}$ \\
\hline 2 & $\begin{array}{l}\text { kategori minor usability problem, permasalahan kegunaan } \\
\text { kecil, perbaikan ini diberikan prioritas yang rendah }\end{array}$ \\
\hline 3 & $\begin{array}{l}\text { ketegori major usability problem, permasalahan kegunaan } \\
\text { utama, perbaikan penting dilakukan, maka dari itu diberikan } \\
\text { prioritas tinggi }\end{array}$ \\
\hline 4 & $\begin{array}{l}\text { kategori usability catastrophe, ditemukan kesalahan fatal. } \\
\text { Permasalahan perbaikan ini wajib dilakukan }\end{array}$ \\
\hline
\end{tabular}

\section{HASIL DAN PEMBAHASAN}

\subsection{UJI VALIDITAS}

Uji validitas menggunakan $r$ tabel dengan signifikasi 0,01 uji satu arah. Item kuisoner dinyatakan valid jika $r$ hitung $>r$ tabel dengan nilai $n 98$ maka didapat df $=98$ maka diperoleh $r$ tabel sebesar 0,252. Artinya jika nilai korelasi lebih besar dari batasan yang ditentukan maka item dianggap valid. Bila korelasi ditentukam kurang dari jumlah yang ditentukan maka item dianggap tidak valid [10]. Hasil dari uji validitas kesepuluh variable dibawah ini:

Tabel 3. Hasil Uji Validitas

\begin{tabular}{cccccc}
\hline Dimensi & & Signifikansi & Responden & $\mathrm{R}$ tabel & Hasil \\
\hline $\mathrm{X} 1.1$ & $<.001$ & & 98 & 0.794 & valid
\end{tabular}


https://journal-computing.org/index.php/journal-sea/index

\begin{tabular}{|c|c|c|c|c|}
\hline $\mathrm{X} 1.2$ & $<.001$ & 98 & 0.672 & valid \\
\hline X1.3 & $<.001$ & 98 & 0.718 & valid \\
\hline X1.4 & $<.001$ & 98 & 0.693 & valid \\
\hline X1.5 & $<.001$ & 98 & 0.745 & valid \\
\hline X2.1 & $<.001$ & 98 & 0.692 & valid \\
\hline$\times 2.2$ & $<.001$ & 98 & 0.644 & valid \\
\hline X2.3 & $<.001$ & 98 & 0.777 & valid \\
\hline X3.1 & $<.001$ & 98 & 0.667 & valid \\
\hline X3.2 & $<.001$ & 98 & 0.668 & valid \\
\hline X3.3 & $<.001$ & 98 & 0.786 & valid \\
\hline X3.3 & $<.001$ & 98 & 0.757 & valid \\
\hline X4.1 & $<.001$ & 98 & 0.489 & valid \\
\hline$X 4.2$ & $<.001$ & 98 & 0.772 & valid \\
\hline X4.3 & $<.001$ & 98 & 0.822 & valid \\
\hline X4.4 & $<.001$ & 98 & 0.673 & valid \\
\hline X5.1 & $<.001$ & 98 & 0.651 & valid \\
\hline X5.2 & $<.001$ & 98 & 0.707 & valid \\
\hline X5.3 & $<.001$ & 98 & 0.705 & valid \\
\hline X6.1 & $<.001$ & 98 & 0.78 & valid \\
\hline X6.2 & $<.001$ & 98 & 0.744 & valid \\
\hline X6.3 & $<.001$ & 98 & 0.776 & valid \\
\hline X7.1 & $<.001$ & 98 & 0.859 & valid \\
\hline X7.2 & $<.001$ & 98 & 0.851 & valid \\
\hline X8.1 & $<.001$ & 98 & 0.523 & valid \\
\hline X8.2 & $<.001$ & 98 & 0.604 & valid \\
\hline X8.3 & $<.001$ & 98 & 0.705 & valid \\
\hline X8.4 & $<.001$ & 98 & 0.771 & valid \\
\hline X9.1 & $<.001$ & 98 & 0.693 & valid \\
\hline X9.2 & $<.001$ & 98 & 0.741 & valid \\
\hline X9.3 & $<.001$ & 98 & 0.766 & valid \\
\hline X9.4 & $<.001$ & 98 & 0.621 & valid \\
\hline X10.1 & $<.001$ & 98 & 0.717 & valid \\
\hline X10.2 & $<.001$ & 98 & 0.655 & valid \\
\hline X10.3 & $<.001$ & 98 & 0.779 & valid \\
\hline
\end{tabular}




\section{Journal of Software Engineering Ampera}

Vol. 2, No. 3, October 2021 e-ISSN: 2775-2488

https://journal-computing.org/index.php/journal-sea/index

\begin{tabular}{lllll}
$\mathrm{X} 10.4$ & $<.001$ & 98 & 0.696 & valid \\
$\mathrm{Y}$ & $<.001$ & 98 & 2 & valid \\
\hline
\end{tabular}

\subsection{UJI RELIABILITAS}

Uji reabilitas ini dilakukan dengan melihat skor rumus Cronbach's Alpha, nilai tersebut menggambarkan indikator yang digunakan dalam penelitian menggunakan aplikasi SPSS 16.0. Metode pengambilan keputusan reabilitas ini diambil menggunakan batasan 0,6. Reabilitas kurang dari 0,6 dianggap kurang baik sedangkan 0,7 dapat diterima dan 0,8 adalah baik [10]. Hasil uji reabilitas dibawah ini:

Tabel 4. Hasil Uji Reabilitas

\begin{tabular}{llll}
\hline Variabel & Total Kuesioner & $\begin{array}{l}\text { Cronbach's } \\
\text { Alpha }\end{array}$ & Hasil \\
\hline X1 & 5 & 0.773 & valid \\
X2 & 3 & 0.694 & valid \\
X3 & 4 & 0.668 & valid \\
X4 & 4 & 0.653 & valid \\
X5 & 3 & 0.643 & valid \\
X6 & 3 & 0.641 & valid \\
X7 & 2 & 0.632 & valid \\
X8 & 4 & 0.611 & valid \\
X9 & 4 & 0.663 & valid \\
X10 & 4 & 0.672 & valid \\
Y & 2 & 1 & valid \\
\hline
\end{tabular}

\subsection{Uji Asumsi Klasik}

\section{Hasil Uji Normalitas}

Berdasarkan hasil output pada Gambar 1 maka dapat dilihat bahwa data menyebar disekitar garis diagonal serta penyebaran mengikuti kemana arah garis diagonal tersebut, maka data tersebut dinyatakan berdistribusi normal. Untuk itu peneliti membuat kesimpulan yaitu pengolahan data $X$ Terhadap $Y$ dikatakan Normal. 


\section{Journal of Software Engineering Ampera}

Vol. 2, No. 3, October 2021 e-ISSN: 2775-2488

https://journal-computing.org/index.php/journal-sea/index

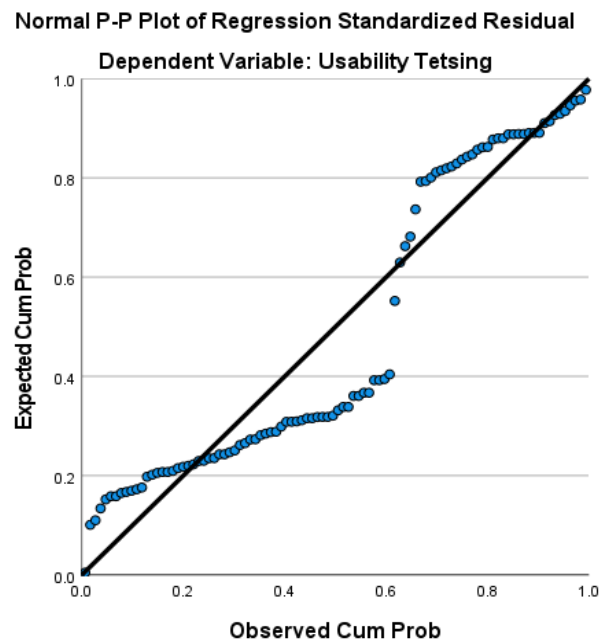

Gambar 1. Grafik P-P UJi Normalitas X Terhadap Y

\section{Hasil Multikoleneritas}

Dalam uji multikoleritas tidak terjadi kejala multikoleneritas jika nilai tolerance $>0,1$ dan nilai VIF <10, dapat dilihat pada tabel 4.22 berikut:

Tabel 5. Hasil Uji Multikonearitas

\begin{tabular}{llll}
\hline No & \multicolumn{1}{c}{ Model } & \multicolumn{1}{c}{ Sig } & Hasil \\
\hline 1 & Visibility of System Status & 0.79 & tidak terjadi multikoreltas \\
2 & $\begin{array}{l}\text { Match Between System and the } \\
\text { Real World }\end{array}$ & 0.031 & tidak terjadi multikoreltas \\
3 & User Control and Freedom & 0.718 & tidak terjadi multikoreltas \\
4 & Consistency and Standards & 0.514 & tidak terjadi multikoreltas \\
5 & Error Prevention & 0.829 & tidak terjadi multikoreltas \\
6 & Recognition rather than Recall & 0.738 & tidak terjadi multikoreltas \\
7 & Flexibility and Efficiency of Use & 0.853 & tidak terjadi multikoreltas \\
8 & Aesthetic and Minimalist Design & 0.438 & tidak terjadi multikoreltas \\
9 & $\begin{array}{l}\text { Help Users Recognize, Diagnose } \\
\text { and Recover from Errors }\end{array}$ & 0.701 & tidak terjadi multikoreltas \\
10 & Help and Documentation & 0.266 & tidak terjadi multikoreltas \\
\hline
\end{tabular}




\section{Journal of Software Engineering Ampera}

Vol. 2, No. 3, October 2021 e-ISSN: 2775-2488

https://journal-computing.org/index.php/journal-sea/index

\section{Hasil Uji Hetoreskedasitas}

Uji Hetoreskedasitas ini menjadi perbedaan varians residual suatu pengamatan keperiode dalam pengamatan lain dimana jika hasil sig <0,05 maka terjadi Hetoreskeditas dan jika nilai sig >0,05 maka tidak terjadi Hetoreskeditas dapat dilihat pada gambar 4.23 Berikut :

Tabel 6. Hasil Uji Hetoreskedasitas

\begin{tabular}{|c|c|c|c|}
\hline No & Model & Sig & Hasil \\
\hline 1 & Visibility of System Status & 0.44 & tidak terjadi hetoroskedasitas \\
\hline 2 & $\begin{array}{l}\text { Match Between System and } \\
\text { the Real World }\end{array}$ & 0.533 & tidak terjadi hetoroskedasitas \\
\hline 3 & User Control and Freedom & 0.5 & tidak terjadi hetoroskedasitas \\
\hline 4 & Consistency and Standards & 0.343 & tidak terjadi hetoroskedasitas \\
\hline 5 & Error Prevention & 0.763 & tidak terjadi hetoroskedasitas \\
\hline 6 & $\begin{array}{l}\text { Recognition rather than } \\
\text { Recall }\end{array}$ & 0.738 & tidak terjadi hetoroskedasitas \\
\hline 7 & $\begin{array}{l}\text { Flexibility and Efficiency of } \\
\text { Use }\end{array}$ & 0.864 & tidak terjadi hetoroskedasitas \\
\hline 8 & $\begin{array}{l}\text { Aesthetic and Minimalist } \\
\text { Design }\end{array}$ & 0.78 & tidak terjadi hetoroskedasitas \\
\hline 9 & $\begin{array}{l}\text { Help Users Recognize, } \\
\text { Diagnose and Recover from } \\
\text { Errors }\end{array}$ & 0.275 & tidak terjadi hetoroskedasitas \\
\hline 10 & Help and Documentation & 0.82 & tidak terjadi hetoroskedasitas \\
\hline
\end{tabular}

\subsection{Hasil pengujian hipotesis}

\section{1. $\quad$ Uji T (Secara Berganda)}

Uji t bertujuan untuk mengetahui ada atau tidaknya pengaruh parsial yang diberikan oleh variable bebas $(X)$ berdasarkan hasil analisis yang peneliti lakukan seperti pada table berikut:

Tabel 7. Uji T

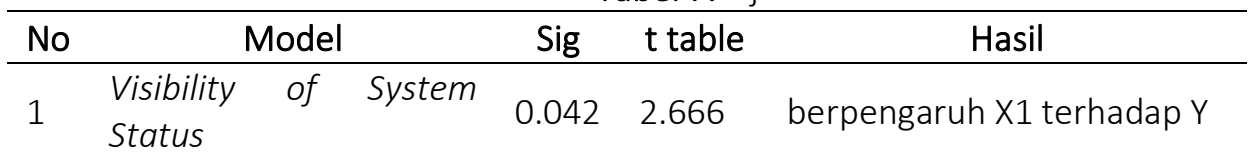




\section{Journal of Software Engineering Ampera}

Vol. 2, No. 3, October 2021 e-ISSN: 2775-2488

https://journal-computing.org/index.php/journal-sea/index

\begin{tabular}{|c|c|c|c|c|}
\hline & $\begin{array}{l}\text { Match Between System } \\
\text { and the Real World }\end{array}$ & 0.031 & 2.187 & berpengaruh $\mathrm{X} 2$ terhadap $\mathrm{Y}$ \\
\hline & $\begin{array}{l}\text { User Control and } \\
\text { Freedom }\end{array}$ & 0.018 & 2.152 & berpengaruh $\mathrm{X} 3$ terhadap $\mathrm{Y}$ \\
\hline & $\begin{array}{l}\text { Consistency } \\
\text { Standards }\end{array}$ & 0.014 & 2.146 & berpengaruh $\mathrm{X} 4$ terhadap $\mathrm{Y}$ \\
\hline & Error Prevention & 0.029 & 2.166 & berpengaruh $X 5$ terhadap $Y$ \\
\hline & $\begin{array}{l}\text { Recognition rather than } \\
\text { Recall }\end{array}$ & 0.038 & 2.336 & berpengaruh $\mathrm{X} 6$ terhadap $\mathrm{Y}$ \\
\hline & $\begin{array}{l}\text { Flexibility and Efficiency } \\
\text { of Use }\end{array}$ & 0.031 & 2.186 & berpengaruh $\mathrm{X} 7$ terhadap $\mathrm{Y}$ \\
\hline & $\begin{array}{l}\text { Aesthetic and } \\
\text { Minimalist Design }\end{array}$ & 0.044 & 2.78 & berpengaruh $X 8$ terhadap $Y$ \\
\hline & $\begin{array}{l}\text { Help Users Recognize, } \\
\text { Diagnose and Recover } \\
\text { from Errors }\end{array}$ & 0.011 & 2.138 & berpengaruh $X 9$ terhadap $Y$ \\
\hline & $\begin{array}{l}\text { Help } \\
\text { Documentation }\end{array}$ & 0.027 & 2.12 & berpengaruh $\mathrm{X} 10$ terhadap $\mathrm{Y}$ \\
\hline
\end{tabular}

\section{Uji F}

Uji $f$ bertujuan untuk mengetahui ada atau tidaknya pengaruh yang diberikan variabel bebas $(X)$ terhadap variabel terikat $(Y)$. Hasil uji $F$ akan menjelaskan hasil Fhitung dan FTabel, hasil didapat adalah sebagai berikut:

Tabel 8. Hasil Uji Annova F

\begin{tabular}{crcc}
\hline Model & Sig & f hitung & Hasil \\
\hline ANNOVA & 0.038 & 24.015 & berpengaruh $\mathrm{X}$ terhadap $\mathrm{Y}$ \\
\hline
\end{tabular}

Tabel 9. Hasil Uji Summary F

\begin{tabular}{cccc}
\hline Model & Sig & R square & Hasil \\
\hline SUMMARY & 0.038 & 0.544 & berpengaruh $\mathrm{X}$ terhadap $\mathrm{Y}$ \\
\hline
\end{tabular}

\subsection{Analisis Data}

Berdasarkan hasil yang sudah didapat dari pengolahan kuesioner dari ke-10 variabel Heuristic Evaluation menunjukkan persepsi pengguna terhadap Sisfo sebagai berikut: 


\section{Journal of Software Engineering Ampera}

Vol. 2, No. 3, October 2021 e-ISSN: 2775-2488

https://journal-computing.org/index.php/journal-sea/index

Tabel 10. Persepsi Pengguna Sisfo

\begin{tabular}{|c|c|c|c|c|}
\hline Variabel & Kode & Hasil & $\begin{array}{l}\text { Severity } \\
\text { rating }\end{array}$ & Keterangan \\
\hline Visibility of System Status & $\mathrm{X} 1$ & 4.18 & 0.836 & Baik \\
\hline $\begin{array}{l}\text { Match Between System } \\
\text { and the Real World }\end{array}$ & $\mathrm{x} 2$ & 4.02 & 1.34 & Baik \\
\hline User Control and Freedom & x3 & 4.07 & 1.017 & Baik \\
\hline $\begin{array}{l}\text { Consistency and } \\
\text { Standards }\end{array}$ & $\mathrm{X} 4$ & 4.12 & 1.03 & Baik \\
\hline Error Prevention & $x 5$ & 4.14 & 1.03 & Baik \\
\hline $\begin{array}{l}\text { Recognition rather than } \\
\text { Recall }\end{array}$ & $x 6$ & 4.01 & 1.33 & Baik \\
\hline $\begin{array}{l}\text { Flexibility and Efficiency of } \\
\text { Use }\end{array}$ & $\mathrm{X} 7$ & 3.91 & 1.95 & Baik \\
\hline $\begin{array}{l}\text { Aesthetic and Minimalist } \\
\text { Design } \\
\text { Help Users }\end{array}$ & $x 8$ & 3.94 & 0.985 & Baik \\
\hline $\begin{array}{l}\text { Recognize, Diagnose and } \\
\text { Recover from Errors }\end{array}$ & $x 9$ & 4.06 & 1.015 & Baik \\
\hline Help and Documentation & X10 & 4.04 & 1.01 & Baik \\
\hline
\end{tabular}

Dari tabel diatas dapat dilihat bahwa Sisfo dalam kondisi baik, dengan begitu juga sisfo telah memberikan pelayanan secara baik ke pengguna dan tidak memerlukan rekomendasi perbaikan

\section{KESIMPULAN}

Berdasarkan hasil penelitian yang didapat dari kuesioner evaluasi User Experience terhadap Sistem Informasi Akademik Universitas Bina Darma menggunakan Heuristic Evaluation maka peneliti memberikan kesimpulan dari kesepuluh (10) varieabel yaitu Visibility of System Status, Match Between System and the Real World, User Control and Freedom, Consistency and Standards, Error Prevention, Recognition rather than Recall, Flexibility and Efficiency of Use, Aesthetic and Minimalist Design, Help Users Recognize, Diagnose and Recover from Errors dan Help and Documentation bahwa persepsi pengguna Sisfo dalam keadaan baik dan 


\section{Journal of Software Engineering Ampera}

Vol. 2, No. 3, October 2021 e-ISSN: 2775-2488

https://journal-computing.org/index.php/journal-sea/index

masuk ke kategori cosmetic problem masalah yang terjadi tidak terlalu mempengaruhi pengguna dan perbaikan tidak terlalu dibutuhkan.

\section{DAFTAR PUSTAKA}

[1] Hasan Syahril, "Analisis Penerimaan Sistem Informasi Akademik (SIAKAD) Pada Politeknik Sains Dan Tekhnologi Wiratama Maluku Utara," J. Elektonic, vol. vol.1, no., 2014.

[2] J. Garrett, The Elements of User Experience: User-Centered Design for the Web and Beyond. 2010.

[3] R. faticha Alfa, "ANALISA USABILITY DESAIN USER INTERFACE PADA WEBSITE TOKOPEDIA MENGGUNAKAN METODE HEURISTICS EVALUATION," teknokompak, vol. Vol. 13, N, 2019.

[4] I. R. Co-operation and I. Organisations, "The Case of the International Organization for Standardization ( ISO )," 2017.

[5] J. Nielsen, "Usability inspection methods," Conf. Hum. Factors Comput. Syst. - Proc., vol. 1994-April, pp. 413-414, 1994, doi: 10.1145/259963.260531.

[6] Prematara Oktabareki, "Analisis UI/UX pada Sistem Informasi Akademik Universitas Sriwijaya Dengan Menggunakan Metode Heuristic Evaluation," J. Wind Eng. Ind. Aerodyn., 2019.

[7] A. Kurniawan, R. I. Rokhmawati, and A. Rachmadi, "Evaluasi User Experience dengan Metode Heuristic Evaluation dan Persona (Studi pada : Situs Web Dalang Ki Purbo Asmoro)," J. Pengemb. Teknol. Inf. dan Ilmu Komput., vol. 2, no. 8, pp. 2918-2926, 2018, [Online]. Available: http://j-ptiik.ub.ac.id.

[8] T. Purnama, I. M. A. Pradnyana, and K. Agustini, "Usability Testing Menggunakan Metode Heuristic Evaluation Pada Aplikasi EMusrenbang Bappeda Kabupaten Badung," J. Pendidik. Teknol. dan Kejuru., vol. 16, no. 1, p. 87, 2019, doi: 10.23887/jptkundiksha.v16i1.17949.

[9] B. Ghina, H. Ma, J. Wong, D. Agushinta, and R. Metty, "Analisis User Experiance Terhadap Website Perpustakaan Universitas Gunadarma Dengan Metode Heuristic Evaluation," J. IIm. Komputasi, vol. 18, no. 3, 2019, doi: 10.32409/jikstik.18.3.2589.

[10] D. A. N. N. Dewi and U. Diponegoro, Modul Uji Validitas dan Reliabilitas. researchgate.net, 2018. 